\title{
Impact of chemoprophylaxis immunisation under halofantrine (CPS-HF) drug cover in Plasmodium yoelii Swiss mice malaria model
}

\author{
Arif Jamal Siddiqui ${ }^{1,3,8,9}$, Jyoti Bhardwaj ${ }^{2,3,8}$, Walid Sabri Hamadou ${ }^{1}$, Manish Goyal ${ }^{3}$, Sadaf Jahan ${ }^{(14}{ }^{4}$, Syed Amir \\ Ashraf $^{5}$, Arshad Jamal ${ }^{1}$, Pankaj Sharma ${ }^{3,6}$, Manojkumar Sachidanandan ${ }^{7}$, Riadh Badraoui $^{1}$, Mejdi Snoussi ${ }^{1}$ and \\ Mohd Adnan $\left.{ }^{1}\right)^{1}$
}

\author{
${ }^{1}$ Department of Biology, College of Science, University of Hail, Hail, Saudi Arabia; \\ ${ }^{2}$ Indiana University, School of Medicine, Indianapolis, Indiana, United States; \\ ${ }^{3}$ Molecular Parasitology and Immunology Division, CSIR-Central Drug Research Institute, Lucknow, India; \\ ${ }^{4}$ Department of Medical Laboratory Sciences, College of Applied Medical Sciences, Majmaah University, Al Majmaah, Saudi Arabia; \\ ${ }^{5}$ Department of Clinical Nutrition, College of Applied Medial Sciences, University of Hail, Hail, Saudi Arabia; \\ ${ }^{6}$ Program in Cellular and Molecular Medicine, Boston Children's Hospital, Boston, MA, U.S.A.; \\ ${ }^{7}$ Department of Oral Radiology, College of Dentistry, University of Hail, Hail, Saudi Arabia; \\ ${ }^{8}$ Both authors have contributed equally to this work and share first authorship; \\ ${ }^{9}$ Corresponding author
}

\begin{abstract}
In the present study, we have investigated the role of antimalarial drug halofantrine (HF) in inducing the sterile protection against challenges with sporozoites of the live infectious Plasmodium yoelii (Killick-Kendrick, 1967) in Swiss mice malaria model. We observed that during the first to third sequential sporozoite inoculation cycles, blood-stage patency remains the same in the control and chemoprophylaxis under HF drug cover (CPS-HF) groups. However, a delayed blood-stage infection was observed during the fourth and fifth sporozoite challenges and complete sterile protection was produced following the sixth sporozoite challenge in CPS-HF mice. We also noticed a steady decline in liver stage parasite load after 3th to 6th sporozoite challenge cycle in CPS-HF mice. CPS-HF immunisation results in a significant up-regulation of pro-inflammatory cytokines (IFN- $\gamma$, TNF- $\alpha$, IL-12 and iNOS) and down-regulation of anti-inflammatory cytokines (IL-10 and TGF- $\beta$ ) mRNA expression in hepatic mononuclear cells (HMNC) and spleen cells in the immunised CPS-HF mice (after 6th sporozoite challenge) compared to control. Overall, our study suggests that the repetitive sporozoite inoculation under HF drug treatment develops a strong immune response that confers protection against subsequent challenges with sporozoites of $P$. yoelii.
\end{abstract}

Keywords: CPS-immunisation, sporozoites, cytokines, Real Time PCR, mRNA expression

Malaria is considered one of the most leading and deadly diseases worldwide. In the year 2019, nearly 229 million new cases of malaria have been stated, resulting in approximately 409 thousand deaths globally (WHO 2019, Siddiqui et al. 2020a, Varo et al. 2021). Thus, a safe, effective and inexpensive vaccine against malaria is urgently warranted to close the gap left by the current intervention strategies (Prakash et al. 2014, Hemingway et al. 2016, Frimpong et al. 2018, Abuga et al. 2021).

Immunisation against the liver stage (clinically silent phase) malaria parasites is represented as an effective approach to induce sterile protective immunity (Bhardwaj et al. 2015, Kurtovic et al. 2020). CPS-immunisation (chemoprophylaxis under antimalarial drugs covers) using the in- fectious sporozoites is one of the vaccination strategies that is gaining widespread attention nowadays. Several studies using mouse malaria models showed the potential of various antimalarial drugs (i.e., chloroquine, arteether, mefloquine, azithromycin, lumefantrine) in producing sterile protection using variable inoculums of viable live sporozoites (Bijker et al. 2015, Bhardwaj et al. 2016, Mordmuller et al. 2017, Siddiqui et al. 2021).

However, there are still many antimalarials drugs available that have the potential to be a good chemoprophylactic agent in CPS-immunisation. Halofantrine (HF) was firstly developed by the Walter Reed Army Research Institute in the 1960s. It is an aminoalcohol structurally related to quinine but belongs to the class of 9-phenanthrene 
methanols (Kolade et al. 2008). HF is well-known blood schizontocidal drug that acts on infected red blood cells such as trophozoites and schizonts stages of malaria parasites (Haidar et al. 2019). HF is not effective against the liver stages of malaria parasites (Haidar et al. 2019), thus making it as an attractive chemoprophylactic agent for CPS-immunisation. In the present study, we have explored the potential of CPS-immunisation methodology using antimalarial drug halofantrine (HF) with live sporozoite inoculations in the murine Plasmodium yoelii (Killick-Kendrick, 1967), N67 chloroquine (CQ) resistant, Swiss Albino mice infection model.

\section{MATERIAL AND METHODS}

\section{Ethical statement}

Ethical approval (No. IAEC/2012/67-N) was obtained from CSIR-Central Drug Research Institute's Institutional Animal Care and Use Committee recognised by Committee for the Purpose of Control and Supervision of Experiments on Animals (CPCSEA), Government of India, to carry out experiments on Swiss Albino mice model. Therefore, all mice (control and experimental) were sacrificed by deep anesthesia using ether.

\section{In vivo experimental model}

Following the Institutional Animal Ethics Committee (IAEC) protocol, we used laboratory-bred female Swiss Albino mice (weight 22-24 g) for whole experiments. Plasmodium yoelii (N67 strain-rodent malaria parasite) was used in this study. The life cycle of parasite and mice were maintained by CSIR-CDRI laboratory and Swiss mice facility, which has been defined in detail previously (Siddiqui et al. 2020b). Swiss mice infected by $P$. yoelii were adopted to nourish mosquitoes Anopheles stephensi Liston by infectious blood meal for getting sporozoites at day 12 from mosquitoes gland (salivary). This methodology was explained earlier with minor changes (Siddiqui et al. 2020b).

Before isolation of sporozoites, we monitored the infection rate in the mosquitoes by seeing the mosquito midgut for the availability of oocysts. On day 12, infected mosquitoes were dissected for the isolation of the salivary gland and ground with a probe in little quantity of RPMI-1640 medium followed by centrifugation at $800 \mathrm{rpm}$ for 2 minutes at $4^{\circ} \mathrm{C}$. After centrifugation, the supernatant was transferred in a separate tube and the occurrence of sporozoites under phase contrast microscope was observed. Hemocytometre was used for counting the sporozoites number and $1 \times 10^{4}$ sporozoites were inoculated in the mice intravenously. Parasitemia was observed in the mice under the microscope after taking the one drop of blood from the tail of mice and stained with thin blood smears.

\section{HF drug preparation and curative dose determination}

HF is water-insoluble, hence the drug was first dissolved in Tween-80 (one to three drops) to make a clear suspension and further diluted in an applicable amount of sterile water (Soni et al. 2015). The HF was administrated orally via syringe gavage in $0.5 \mathrm{ml}$ volume per mice as milligram/kilogram/day. The curative blood schizonticidal dosage of HF drug was determined by inoculating the groups of mice ( $\mathrm{n}=10$, each group) intraperitoneally with $1 \times 10^{6} \mathrm{P}$. yoelii infected red blood cells (iRBCs) followed by administration of various doses of $\operatorname{HF}$ drug $(0.5,1,2.5$, and 5 $\mathrm{mg} / \mathrm{kg} /$ day). The drug dosing continued from the day of $P$. yoelii infection to the 3 following days $(0$ to +3$)$. The untreated control group mice $(n=10)$ received the same vehicle used for making the HF drug. Following post iRBC inoculation, parasitemia was monitored daily in both control and HF drug-treated groups throughout the experimental observation period (28 days). The group of mice that did not develop the parasitemia (erythrocytic stage infection) up to 26-28 days was considered as cured.

\section{HF drug treatment and immunisation procedure}

For the CPS-HF immunisation, a group of female Swiss mice was used. A total of 100 mice $(n=100)$ were injected with freshly isolated $1 \times 10^{4} \mathrm{P}$. yoelii sporozoites via intravenous route, while 15 mice $(n=15)$ were injected with salivary gland debris from uninfected mosquitoes (as control) (Fig. 1). After 48h post sporozoites infection, the curative dose $(2.5 \mathrm{mg} / \mathrm{kg} /$ day $)$ of $\mathrm{HF}$ drug was administrated in sporozoite-infected mice group $(\mathrm{n}=85)$, while 15 mice from the same group $(n=15)$ were left untreated as primary inoculum. HF dosing was continued for four days at the curative dose of $2.5 \mathrm{mg} / \mathrm{kg} /$ day. The HF untreated control mice $(n=15)$ were used to check the blood-stage infection (percentage parasitemia, $\mathrm{n}=5)$, liver load $(\mathrm{n}=5)$, and cytokines expression $(\mathrm{n}=5)$ by RT-PCR after primary sporozoites infection.

Blood stage infection from control and CPS-HF treated mice was checked during the entire experimental course and continued until the 21 st day post $P$. yoelii sporozoite infection. Following the primary inoculation, HF-treated mice $(\mathrm{n}=70)$ were again infected with the same number of $P$. yoelii sporozoites (i.e., $1 \times 10^{4}$ ) (1st challenge). However, some mice $(n=15)$ were again kept as an untreated control group (without HF) to monitor the parasite burden in the blood $(\mathrm{n}=5)$, liver $(\mathrm{n}=5)$, and the cytokines expression analysis $(n=5)$ as 1 st challenge. The remaining mice $(\mathrm{n}=70)$ were further treated with HF drug after $48 \mathrm{~h}$ post sporozoites infection as described above.

The infection-treatment cycle was repeated till the complete absence of blood-stage patency in the sequentially withdrawn HF untreated control mice ( $\mathrm{n}=10$ for $2 \mathrm{nd}$, 4th, and 5th challenge and $\mathrm{n}=15$ for $3 \mathrm{rd}$ and 6 th challenge). The criteria of sterile protection were defined as the complete absence of erythrocytic blood-stage infection till the 28th day of the observation period (after post sporozoite infection). Once the sterile protection was achieved, some of the remaining mice of the CPS-HF immunised group $(\mathrm{n}=10)$ were finally challenged with $P$. yoelii $1 \times 10^{4}$ sporozoites $(\mathrm{n}=5)$ and $1 \times 10^{6}$ infected RBCs $(\mathrm{n}=5)$. Additionally, a group of mice $(\mathrm{n}=10)$ was also added as naive control which was also challenged with the same quantity of either $P$. yoelii sporozoites $\left(1 \times 10^{4}\right)$ or iRBC $\left(1 \times 10^{6}\right)$. Following sporozoites and iRBC challenge, the mice were monitored to check the blood-stage infection by Giemsa staining (percentage parasitemia).

\section{Determination of pre-erythrocytic stage parasite burden by Real Time PCR}

The presence or absence of pre-erythrocytic stage parasite load following sporozoites of $P$. yoelii injected intravenously in the experimental mice were determined by the Real-Time PCR (RT-PCR) assay, details described as previously (Siddiqui et al. 2012, 2015). The liver was individually isolated from untreated control $(n=5)$ and CPS-HF $(n=5)$ groups of mice after 40 hours post sporozoite 


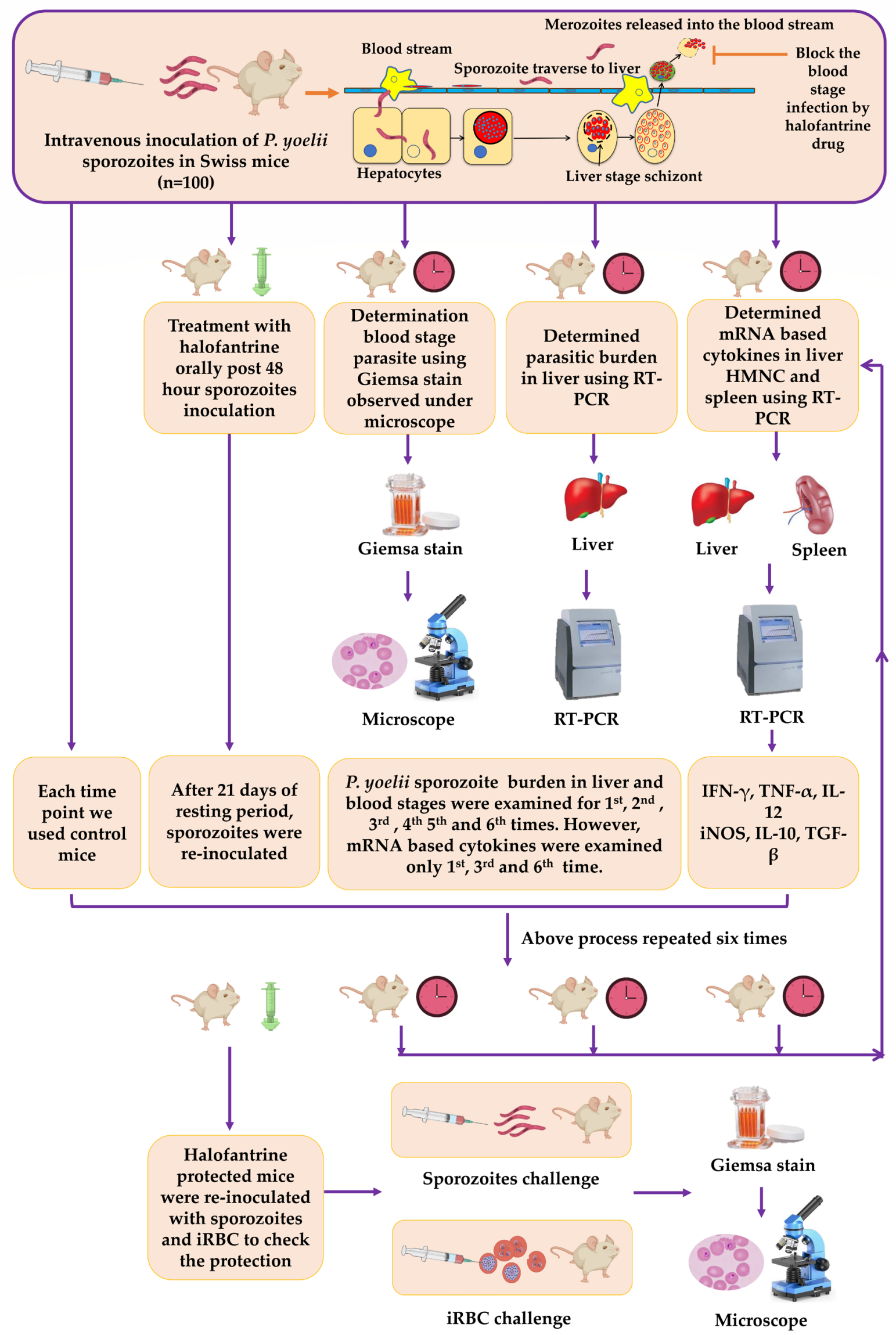

Fig. 1. Diagrammatic representation of the experimental protocol for the Plasmodium yoelii (Killick-Kendrick, 1967) sporozoite inoculation/challenge under halofantrine drug cover. 
Table 1. Forward and reverse primer sequences used for quantitative RT-PCR to quantify parasite burden with liver stages of Plasmodium yoelii (Killick-Kendrick, 1967) and estimation of mRNA expression-based cytokines.

\begin{tabular}{|c|c|}
\hline Gene & Primer sequence \\
\hline \multirow{2}{*}{ 18S rRNA } & Forward 5'GGGGATTGGTTTTGACGTTTTTGCG 3' \\
\hline & Reverse 5'AAGCATTAAATAAAGCGAATACATCCTTAT \\
\hline \multirow{2}{*}{ GAPDH } & Forward 5' ACAGTCAAGGCCGAGAATGGG 3' \\
\hline & Reverse 5'GCCGGTGCTGAGTATGTCGT 3' \\
\hline \multirow{2}{*}{ IFN- $\gamma$} & Forward 5' GTTACTGCCACGGCACAGTCATTG 3' \\
\hline & Reverse 5'ACCATCCTTTTGCCAGTTCCTCCAG 3' \\
\hline \multirow{2}{*}{ TNF- $\alpha$} & Forward 5' CCGATGGGTTGTACCTTGTCT 3' \\
\hline & Reverse 5'GTGGGTGAGGAGCACGT \\
\hline \multirow{2}{*}{ IL-12 } & Forward 5' GGAAGCACGGCAGCAGAATA 3' \\
\hline & Reverse 5' \\
\hline \multirow{2}{*}{ iNOS } & Forward 5' TCCTCACTGGGACAGCACAGAATG 3' \\
\hline & ETGCC 3' \\
\hline \multirow{2}{*}{ IL-10 } & Forward 5' TTTGAATTCCCTGGGTGAGAA 3' \\
\hline & Reverse 5'ACAGGGGAGAAATCGATGACA 3' \\
\hline \multirow{2}{*}{ TGF- $\beta$} & Forward 5'AACTATTGCTTCAGCTCCACAG 3' \\
\hline & Reverse 5'AGTTGGCATGGTAGCCCTTG 3' \\
\hline
\end{tabular}

challenge and homogenised in $15 \mathrm{ml}$ Trizol reagent $(\mathrm{Sigma} \AA$, St Louis, Missouri, USA). After the homogenisation, RNA from the mouse liver sample was isolated from both groups (control and CPS-HF) of immunised mice, and quantification of RNA was done using NanoDrop ${ }^{\circledR}$ technology. Subsequently, isolated RNA was then converted to cDNA, and finally, cDNA was stored at $-20^{\circ} \mathrm{C}$ for further experiments. RT-PCR methodology was completed following our previously published study (Siddiqui et al. 2020b). Furthermore, the pre-erythrocytic stage parasite load or the number of parasites was monitored by considering the $P$. yoelii definite $18 \mathrm{~S}$ rRNA (copy number) in untreated control and CPS-HF immunised mouse liver. For the percent of parasitemia (erythrocytic stage parasite infection), in both groups of mice from untreated control $(\mathrm{n}=5)$ and CPS-HF $(\mathrm{n}=5)$ groups were tested every day and infection rate of erythrocytic stage patency by the standard method (Giemsa staining of thin blood smears) was routinely checked.

\section{Monitoring of mRNA-based cytokines expression in the HMNC liver and spleen}

The mRNA-based cytokine expression of pro- and anti-inflammatory responses in liver HMNC and spleen in control and CPS-HF groups was monitored using the RT-PCR. Firstly, HMNC were isolated from the liver via perfusion using $1 \mathrm{X}$ PBS buffer as described previously with minor modifications (Siddiqui et al. 2020b). In brief, Swiss Albino mice were anesthetised by deep anesthesia and incision was made on the stomach using a scissor, and needle of the syringe was injected into the specific portal vein. Afterward, mouse vein (inferior vena cava) was cut to permit the drainage of blood to rule out the contamination of peripheral blood monocytes and the liver was perfused with $25-50 \mathrm{ml}$ of $1 \mathrm{X}$ PBS buffer ( $\mathrm{pH}$ 7.2). Later, completion of the liver perfusion, the liver was meshed on a cell-specific strainer to concoct a single HMNC suspension and then was centrifuged at $80 \mathrm{~g}$ for 2 minutes at $25^{\circ} \mathrm{C}$. After centrifugation, HMNC supernatant was collected in the new tube and again centrifuged at $460 \mathrm{~g}$ for 7 minutes at $25^{\circ} \mathrm{C}$. Then, HMNC supernatant was thrown away carefully to start making the Percoll gradient. For this, the HMNC pellet was dissolved in $6 \mathrm{ml}$ of $40 \%$ Percoll (Sigma ${ }^{\circledR}$ ), afterwards gently put over $3 \mathrm{ml}$ of $70 \%$ Percoll. Then, the Percoll gradient tube was centrifuged at $800 \mathrm{~g}$ for 25 minutes at $25^{\circ} \mathrm{C}$ to make the final separation of HMNC. After centrifugation, the central layer containing HMNC was carefully taken out and placed into the new tube and a double volume of $1 \mathrm{X}$ PBS buffer was added and mixed properly. This tube was placed again for centrifugation at $800 \mathrm{~g}$ for 6 minutes at $25^{\circ} \mathrm{C}$ and then HMNC supernatant was thrown away. Finally, the lysis buffer for isolating total RNA was added.

In the next step, the spleen from mice was carefully removed and crushed on a $70 \mathrm{~mm}$ specific cell strainer and the single-cell suspension was prepared in $1 \mathrm{X}$ PBS buffer. This single-cell suspension was then centrifuged at $450 \mathrm{~g}$ for 6 minutes and the supernatant was thrown away. Pellet was washed two times using $1 \mathrm{X}$ PBS buffer and then centrifuged at $450 \mathrm{~g}$ for 6 minutes at $6^{\circ} \mathrm{C}$. Total RNA was isolated from liver HMNC and spleen using the RNA isolation kit (Cat no. 74106, Qiagen ${ }^{\circledR}$ Hilden, Germany), and it was then converted to cDNA using Thermofisher ${ }^{\circledR}$ cDNA synthesis kit. Later, cDNA was used as a template for RT-PCR. Finally, reaction conditions of the RT-PCR were set at primary denaturation; $95^{\circ} \mathrm{C}$ for $5 \mathrm{~min}$, followed by amplification of the target cDNA for 45 cycles at $95^{\circ} \mathrm{C}$ for 15 seconds (denaturation), $60^{\circ} \mathrm{C}$ for 25 seconds (annealing), and $72^{\circ} \mathrm{C}$ for 30 seconds (extension). GAPDH (glyceraldehyde 3-phosphate dehydrogenase) was used as a housekeeping gene. All primers for mRNA expression of pro- and anti-inflammatory cytokines are listed in Table 1. Gene Runner ${ }^{\circledR}$ software version 3.05 was used for primer designing.

\section{Statistical analysis}

In this study, Student's $t$-test was used to calculate the significant changes between control and CPS-HF immunised groups. The $p$-value has been denoted with the level of significance as $\mathrm{p} \leq$ $0.05(*), \mathrm{p}<0.005(* *)$ and $\mathrm{p}<0.001(* * *)$ correspondingly. The

Table 2. Determination of blood schizonticidal curative doses of halofantrine (HF) in Swiss Albino mice model. Table representing the time to malaria infection following Plasmodium yoelii (Killick-Kendrick, 1967) iRBCs infection. To determine the curative doses of HF, groups of mice $\left(\mathrm{n}=10\right.$, each group) was infected with P. yoelii iRBCs $\left(1 \times 10^{6}\right)$ intraperitoneal and treated with different doses of $\mathrm{HF}(0.5,1,2.5$ and $5 \mathrm{mg} / \mathrm{kg})$ on the day of $P$. yoelii infection and for three subsequent days $(0$ to +3$)$. Parasitemia was checked regularly using microscopic observation of thin blood smears.

\begin{tabular}{|c|c|c|c|c|c|c|c|c|c|c|}
\hline \multirow{2}{*}{$\begin{array}{l}\text { Doses mg/ } \\
\mathrm{kg} / 4 \text { days }\end{array}$} & \multirow{2}{*}{$\begin{array}{l}\text { Number } \\
\text { of mice }\end{array}$} & \multicolumn{9}{|c|}{ Number of mice showing nil percent parasitemia on day } \\
\hline & & 4 & 5 & 6 & 8 & 12 & 16 & 20 & 24 & 28 \\
\hline \multicolumn{11}{|l|}{ HF drug } \\
\hline 5 & 10 & 10 & 10 & 10 & 10 & 10 & 10 & 10 & 10 & 10 \\
\hline 2.5 & 10 & 10 & 10 & 10 & 10 & 10 & 10 & 10 & 10 & 10 \\
\hline 1 & 10 & 10 & 9 & 5 & 0 & 0 & 0 & 0 & 0 & 0 \\
\hline 0.5 & 10 & 0 & 0 & 0 & 0 & 0 & 0 & 0 & 0 & 0 \\
\hline Control & 10 & 0 & 0 & 0 & 0 & 0 & 0 & 0 & 0 & 0 \\
\hline
\end{tabular}



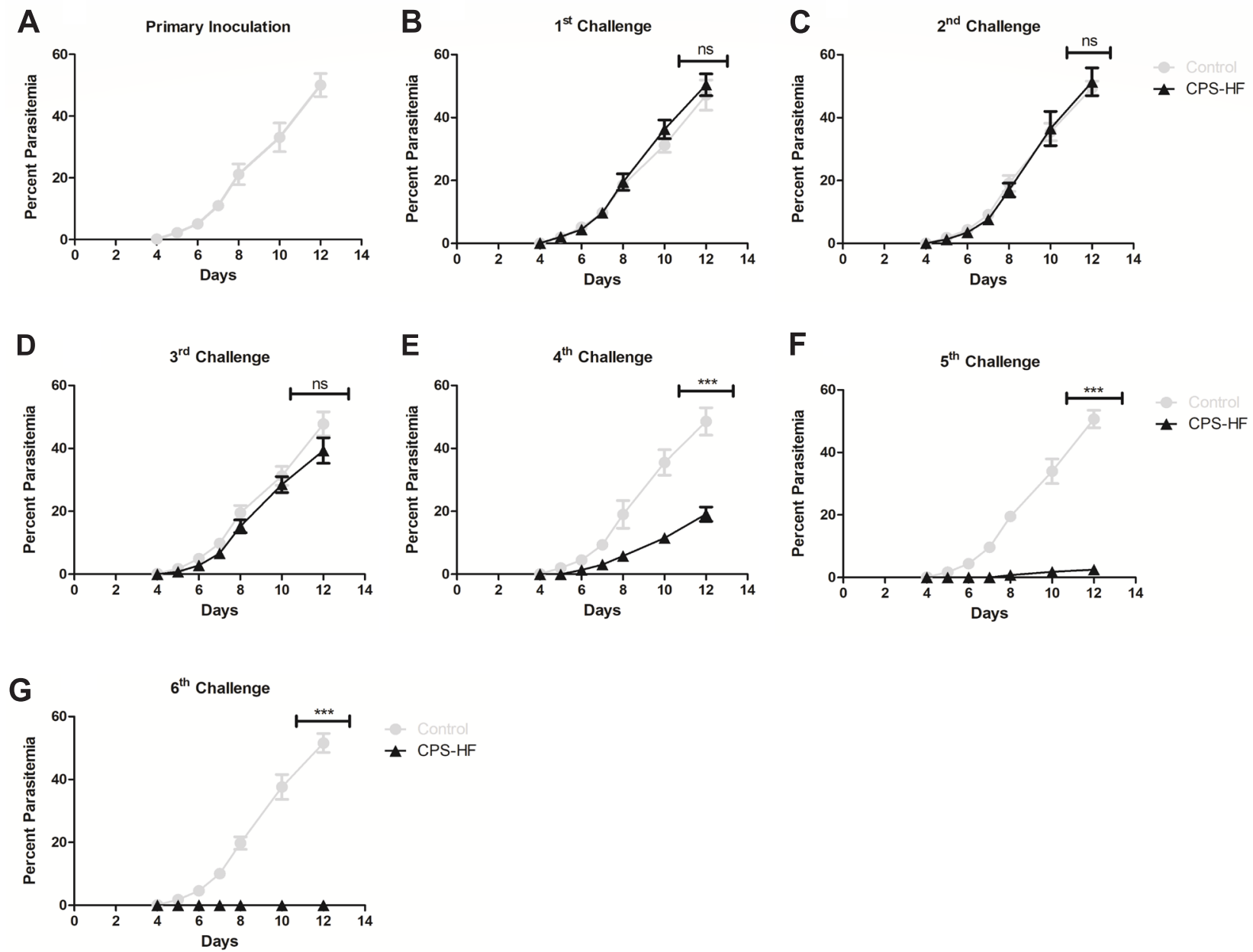

Fig. 2. Outcome of immunisation with sporozoites of Plasmodium yoelii (Killick-Kendrick, 1967) in mice under halofantrine prophylaxis (CPS-HF) on blood-stage patency. Y-axis shows mean \pm SD $(n=5)$ percent parasitemia of HF untreated withdrawn mice $(n=5)$ from each sequential CPS-HF cycle (primary inoculation and following challenge) and the $\mathrm{x}$-axis corresponds to days post sporozoite infection. Statistical significances between different groups were determined using student's $t$-test (indicates $* * * \mathrm{P}<0.001$ and ns $\mathrm{P}>0.05$ ).

data calculation and graphs were made using GraphPad Prism 5.0. Values are represented as mean $\pm \mathrm{SD}$.

\section{RESULTS}

\section{Curative dose determination of halofantrine}

In this experiment, we found that treatment of mice with HF (2.5 and $5 \mathrm{mg} / \mathrm{kg} /$ day for 4 days) provides complete protection against infection with Plasmodium yoelii since none of the mice developed parasitemia during the observation period. However, the lower doses of HF (i.e., 0.5 and $1 \mathrm{mg} / \mathrm{kg} /$ day) were unable to provide complete protection from the blood-stage infection, as shown in Table 2. Based on this experiment we decided to go with $2.5 \mathrm{mg} / \mathrm{kg}$ dose of HF as a curative dose for rest of our experiments.

\section{Effect of continuous inoculation of $P$. yoelii sporozoites under HF prophylaxis}

We observed that after the primary sporozoite inoculation, HF untreated mice developed a blood-stage infection at day 4 post sporozoites inoculation, which further reached $\sim 45 \%$ parasitemia at day 12 post sporozoites infection (Fig. 2A). Similarly, HF treated mice after 1st challenge or
HF treated mice that were rested for 21 days and re-challenged (after 2nd and 3rd challenge) developed blood-stage patency like control HF untreated mice (Fig. 2B-D). Conversely, after 4th and 5th sporozoites challenge, CPS-HF group mice showed a slight delay in the time of blood-stage patency and percentage parasitemia, when compared with HF untreated control mice (Fig. 2E,F). Intriguingly, after the 6th sporozoites challenge, we observed complete sterile protection in mice withdrawn from the CPS-HF group (without HF cover) as none of the mice developed a blood-stage infection during the entire surveillance period of 21 days. As opposed to this, control mice developed patent blood-stage infection on day 4 (Fig. 2G). In brief, these results suggested that repetitive sequential live infectious sporozoites inoculation under HF drug cover advance sterile protection in mice.

\section{Assessment of liver-stage parasite burden during the CPS-HF immunisation}

In parallel, we compared the liver stage parasite burden between the control untreated and CPS-HF immunisation group through RT-PCR assay. We observed that the liver stage parasite burden did not show any difference after the primary, 1st and 2nd sporozoites challenge (Fig. 3A,B). 

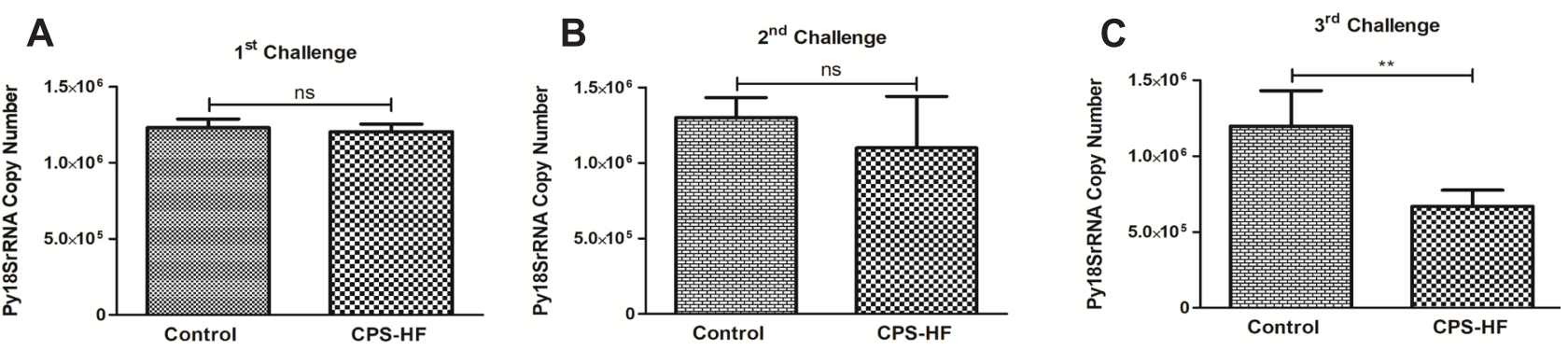

D

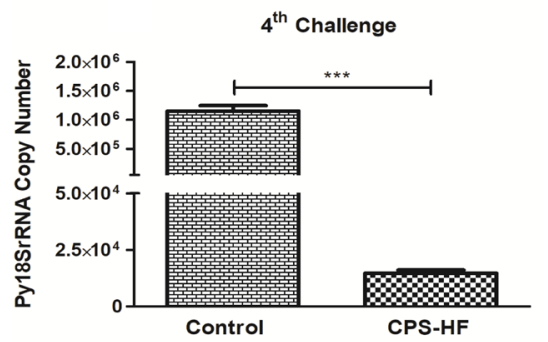

E

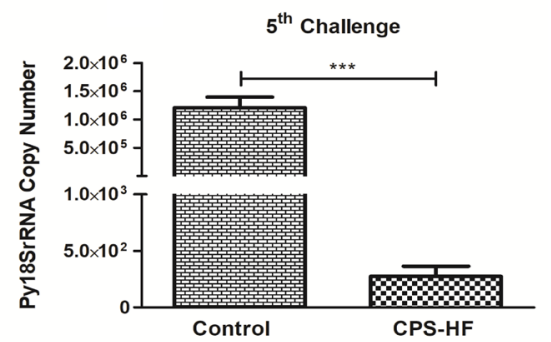

$\mathbf{F}$

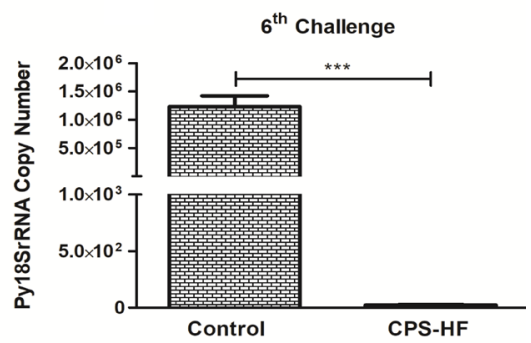

Fig. 3. Determination of pre-erythrocytic liver stage burden of Plasmodium yoelii (Killick-Kendrick, 1967) after CPS-HF prophylaxis. To evaluate the parasite burden in control sporozoite-infected (HF untreated, $n=5$ ) and sporozoite-infected, HF drug-treated mice $(n=5)$ from each sequential CPS-HF cycle (1st to 6th challenge) were assessed via Real-time PCR by calculating the relative fold change of the Py18S rRNA gene normalised to the mouse housekeeping gene (GAPDH). The y-axis shows mean \pm SD $(n=5)$ values of Py18S rRNA copy numbers. Statistical significances between different groups were determined using student's $t$-test (indicates $* * *$ $\mathrm{P}<0.001, * * \mathrm{P}<0.01$ and $\mathrm{ns} \mathrm{P}>0.05)$.

A

IFN- $\gamma$

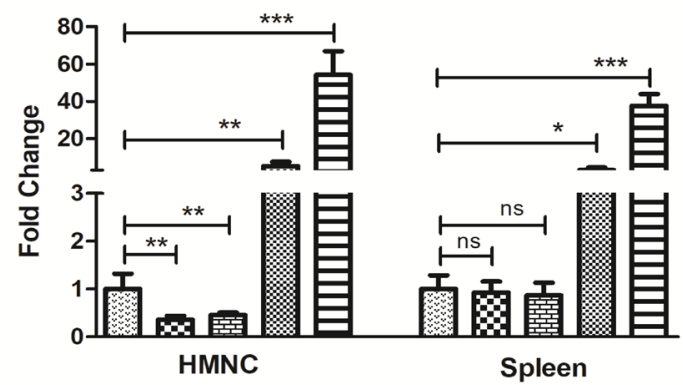

C

IL-12

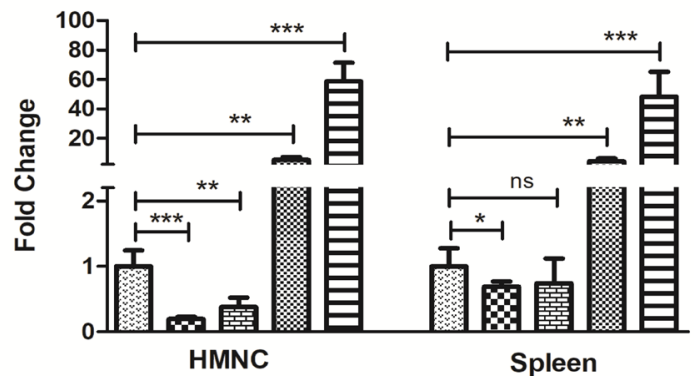

B

TNF- $\alpha$

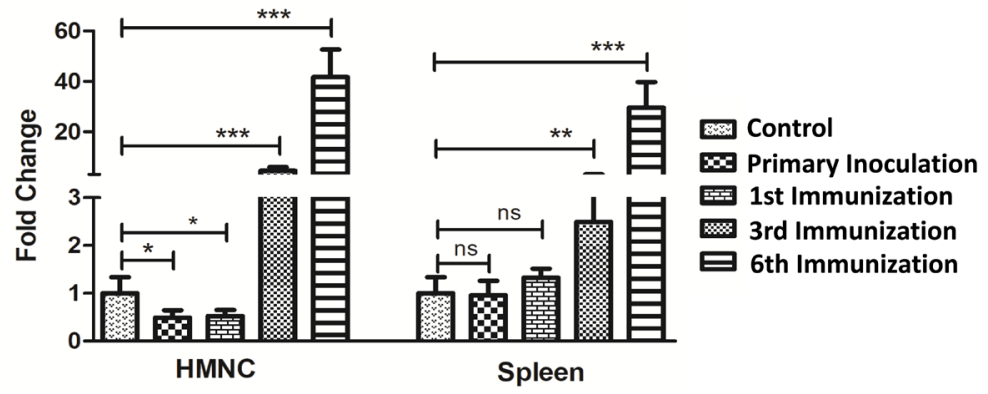

iNOS

Fig. 4. Relative mRNA expression of pro-inflammatory cytokines in liver and spleen cells determined by RT-PCR. Liver HMNCs and spleen cells were isolated from control uninfected mice and mice infected with sporozoites of Plasmodium yoelii $(\mathrm{n}=5)$ at different time points during infection and challenge cycles i.e. $40 \mathrm{~h}$ post-infection. Each bar represents the mean $\pm S D(n=5)$ relative fold changes of corresponding cytokines in liver and spleen. Statistical significances between different groups were determined using student's $t$-test (indicates $* * * \mathrm{P}<0.001, * * \mathrm{P}<0.01, * \mathrm{P}<0.05$ and $\mathrm{ns} \mathrm{P}>0.05$ ). 
However, significant reduction was seen in pre-erythrocytic stage parasite burden $(667619 \pm 108054,14765 \pm 1299$ and $275 \pm 9018 \mathrm{~S}$ rRNA copy number recorded, respectively) after 3rd, 4th and 5th sporozoites challenge, when compared to control group (1196964 $\pm 233363,1152619$ \pm 95413 and $1211119 \pm 18734218 \mathrm{~S}$ rRNA copy number recorded respectably) (Fig. 3C,D,E). Moreover, in the 6th sporozoite challenge group the pre-erythrocytic stage parasite load was almost none (complete reduction) when compared with the control group (Fig. 3F).

\section{Determination on pro-inflammatory cytokines during CPS-HF immunisation in liver and spleen}

Next, we checked the mRNA-based cytokines expression in liver HMNC and spleen of control and CPS-HF immunised group of mice. Pro-inflammatory cytokines such as interferon-gamma (IFN- $\gamma$ ) (Fig. 4A), tumor necrosis factor-alpha (TNF- $\alpha$ ) (Fig. 4B), interleukin-12 (IL-12) (Fig. 4C), and inducible nitric oxide synthase (iNOS) (Fig. 4D) were examined after repetitive sporozoite inoculation in the mice at $1 \mathrm{st}, 3 \mathrm{rd}$ and 6 th sporozoite challenge ( $\mathrm{n}=5$ each time). The results showed that the mRNA expression of pro-inflammatory cytokines; IFN- $\gamma$, TNF- $\alpha$, IL-12, and iNOS were significantly down-regulated $(0.45 \pm 0.05,0.53 \pm 0.12,0.38 \pm 0.14$ and $0.33 \pm$ 0.08 relative fold, respectively) in liver HMNC after 1st sporozoite challenge, when compared with the untreated control group (Fig. 4A-D). After 3rd sporozoite challenge, the mRNA expression of these cytokines (IFN- $\gamma$, TNF- $\alpha$, IL-12, and iNOS) $(5.18 \pm 2.26,4.53 \pm 1.37,5.31 \pm 1.96$ and $6.39 \pm 2.89$ relative fold, respectively) were upregulated. Following the 6th challenge with sporozoites, the mRNA expression of IFN- $\gamma$, TNF- $\alpha$, IL-12, and iNOS were upregulated significantly in the CPS-HF immunised mice $(54.2 \pm 12.7,41.6 \pm 11.1,58.7 \pm 12.6$, and $62.1 \pm 9.0$ relative fold, respectively), when compared with the untreated control group (Fig. 4A-D).

Furthermore, we also monitored the mRNA expression of pro-inflammatory cytokines in mouse spleen after re- petitive sporozoites challenge at 1 st, 3 rd and 6th immunisation periods. After the 1st sporozoites challenge, no significant changes were observed in mRNA expression of IFN- $\gamma$, TNF- $\alpha$, and IL-12 in the CPS-HF immunised mouse spleen, whereas, iNOS mRNA expression $(0.35 \pm$ 0.08 relative fold) was found to be downregulated in the CPS-HF immunised mice when compared with the untreated control group. Furthermore, we found upregulation of mRNA expression for all these cytokines successively from the $3 \mathrm{rd}$ sporozoite challenge to 6th sporozoite challenge in the CPS-HF immunised mouse spleen (37.6 \pm 6.2 , $29.5 \pm 10.2,48.3 \pm 16.9$ and $41.0 \pm 11.2$ relative fold, respectively), when compared with the untreated control group (Fig. 4A-D).

\section{Determination on anti-inflammatory cytokines during CPS-HF immunisation in the liver and spleen}

To check the role of anti-inflammatory cytokines, the mRNA expression level of interleukin-10 (IL-10) (Fig. 5A) and transforming growth factor-beta (TGF- $\beta$ ) (Fig. $5 \mathrm{~B})$ was analysed during the CPS-HF immunisation (i.e., 1st, 3rd and 6th sequential sporozoite challenge) in the mice. The mRNA expression of these anti-inflammatory cytokines (IL-10 and TGF- $\beta$ ) showed significant up-regulation in the CPS-HF immunised group of mouse liver HMNC (7.2 \pm 1.8 and $4.6 \pm 1.7$ relative fold, respectively) after 1 st sporozoite challenge. However, after the 3rd sporozoite challenge mRNA expression of TGF- $\beta$ remains unchanged (Fig. 5B), whereas IL-10 mRNA expression showed significantly upregulated $(2.27 \pm 0.76$ relative fold $)$ in the CPS-HF immunised mice when compared with the control group (Fig. 5A). Following the 6th CPS-HF immunisation, a significant drop in mRNA expression of anti-inflammatory cytokines was noted in the CPS-HF immunised mouse liver HMNCs (that are $0.18 \pm 0.01$ and $0.09 \pm 0.02$ relative fold, respectively), when compared with control groups (Fig. 5A,B).

Similarly, the mRNA expression of IL-10 and TGF- $\beta$ was significantly up-regulated in the spleen of CPS-HF immunised mice after 1st and 3rd sporozoite challenge, when
A

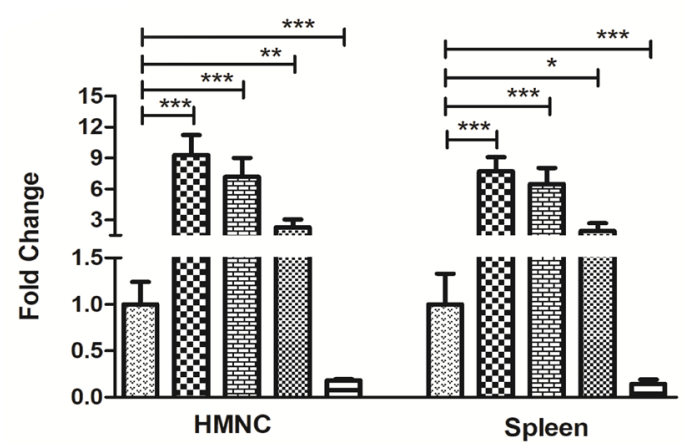

B

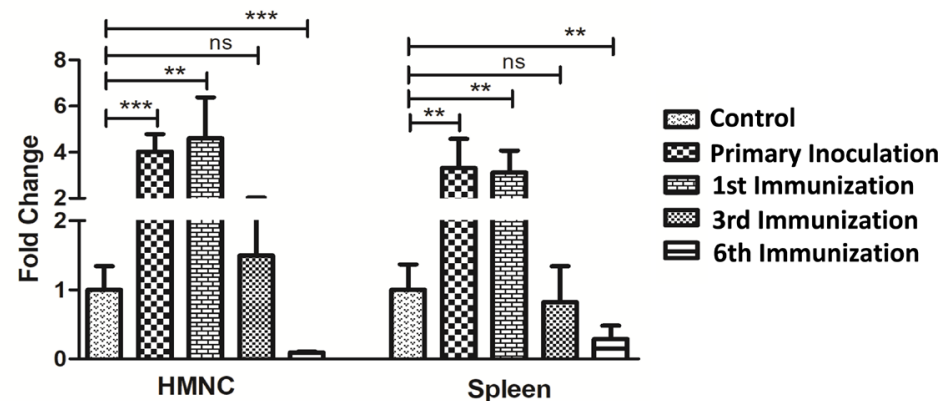

Fig. 5. Relative mRNA expression of anti-inflammatory cytokines in liver and spleen cells determined by RT-PCR. Liver HMNCs and spleen cells were isolated from control uninfected mice and mice infected with sporozoites of Plasmodium yoelii (Killick-Kendrick, 1967) $(\mathrm{n}=5)$ at different time points during infection and challenge cycles i.e., $40 \mathrm{~h}$ post-infection. Each bar represents the mean $\pm \mathrm{SD}$ $(\mathrm{n}=5)$ fold changes of respective cytokines (IL-10, and TGF- $\beta$ ) in HMNCs and splenocytes. Statistical significances between different groups were determined using student's $t$-test (indicates $* * * \mathrm{P}<0.001, * * \mathrm{P}<0.01, * \mathrm{P}<0.05$ and $\mathrm{ns} \mathrm{P}>0.05$ ). 


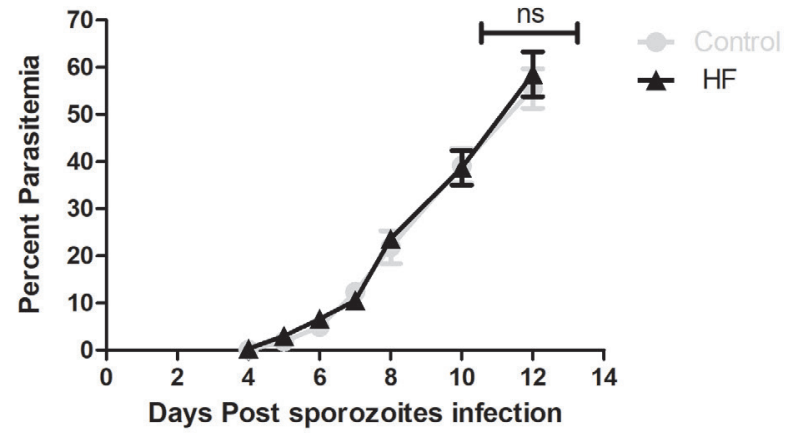

Fig. 6. Residual effect of Halofantrine drug on prophylaxis control. The y-axis shows the mean $(n=5)$ percent parasitemia of mice from each group, as determined by microscopy of Giemsa-stained thin blood smears. The $\mathrm{x}$-axis corresponds to days post sporozoites infection. Error bars represent standard deviation (SD). Statistical significances between different groups were determined using student's $t$-test (indicates ns $\mathrm{P}>0.05$ ).

compared with the untreated group. In the 6th sporozoite challenge, it was found that the mRNA expression of IL10 and TGF- $\beta$ were significantly down-regulated $(0.14$ \pm 0.05 and $0.29 \pm 0.19$ relative fold, respectively) in the CPS-HF immunised group compared with the untreated group (Fig. 5A,B). Collectively, these results showed the down-regulation of anti-inflammatory cytokines (after the 6th sporozoite challenge).

\section{Determination of the residual effect of HF drug}

The residual effect of HF drug $(2.5 \mathrm{mg} / \mathrm{kg})$ was studied using mice that had continuously received (each time point after 28 days interval) the consecutive drug treatment ( 5 times with a four days 0 to +3 dose regime) without infection with sporozoites of $P$. yoelii as drug prophylactic control group. This prophylactic group of mice was challenged with $P$. yoelii sporozoites $\left(1 \times 10^{4}\right)$ after 28 days of the last HF drug administered (Fig. 6). The results of this study showed that the prophylactic group and control group mice developed blood-stage parasitemia on almost the same day and therefore eliminates the possibility of residual HF drug in mice.

\section{Sporozoite and iRBC challenge studies in post- immunised mice}

To verify the stage specificity of CPS-HF induced immunity we challenged the CPS-HF protected mice (after the 6 th sporozoite challenge) with the $P$. yoelii sporozoites $\left(1 \times 10^{4}\right)$ or/and iRBC $\left(1 \times 10^{6}\right)$ (Fig. 7). We observed that following the sporozoite challenge the CPS-HF immunised mice did not develop erythrocytic stage patency during the entire observation period, while the naive control group developed erythrocytic stage infection (Fig. 7A). However, when the mice were challenged with $\mathrm{R} B \mathrm{BC}$ both the naive control and CPS-HF immunised group of mice developed the blood-stage infection (parasitemia). Nevertheless, the CPS-HF immunised group of mice showed 6-7 days delay in blood-stage infection when compared to the naïve control group (Fig. 7B).

\section{DISCUSSION}

Malarian plasmodia enter the human host as sporozoites, infect the liver cells and develop into liver-stage parasites. During the liver stage development, the parasite uses several mechanisms to suppress the host immune response to protect itself and to initiate blood-stage parasite infection. In this respect, the liver stage of the malaria parasite is clinically important to study the host-immune response for future vaccine development. In the recent past, the CPS immunisation approach was widely used to develop liver-stage immunity against sporozoite challenge in mice using the rodent malaria model.

In the present study, we have determined the curative dose of HF drug in mice under our experimental condition using Plasmodium yoelii. We also studied the CPS-immunisation process in the mice through HF drug cover using pre-erythrocytic stage parasite load and erythrocytic stage infection as study points. The results suggest that the CPS-HF immunisation induced immunity after the 6th
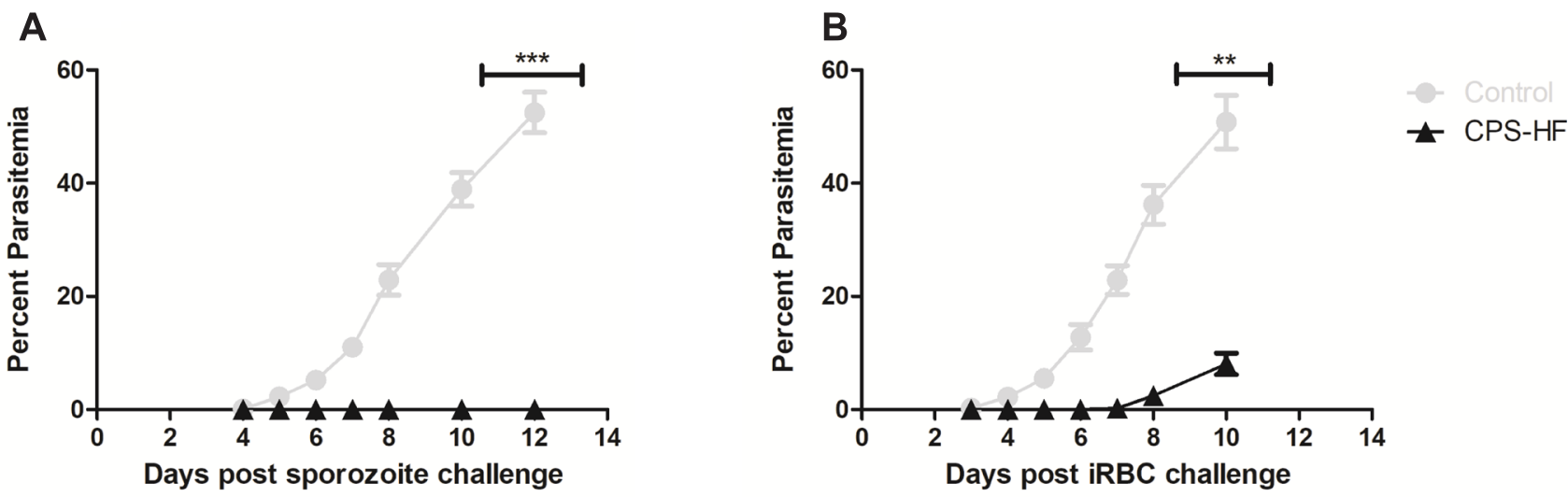

Fig. 7. Post immunisation challenge studies in CPS-HF immunised mice. Mice protected following CPS-HF immunisation were challenged with $1 \times 10^{4}$ sporozoites of Plasmodium yoelii (Killick-Kendrick, 1967) or $1 \times 10^{6} \mathrm{iRBCs}$. Graphs show the mean $\pm \mathrm{SD}(\mathrm{n}=5)$ percent parasitemia following sporozoite and iRBCs challenge in CPS-HF immunised and naïve control groups of mice. Statistical significances between different groups were determined using student's $t$-test (indicates $* * * \mathrm{P}<0.001$ and $* * \mathrm{P}<0.01$ ). 
sequential sporozoite challenge in the mice. In our study, we also determined the role of anti-blood stage immunity in protection against sporozoite challenges. We found that the mice which showed complete sterile protection against sporozoite challenge and developed blood-stage patency after the iRBC challenge. This implies that the immunity developed only to pre-erythrocytic stage parasite, while the CPS-HF immunised group of mice was susceptible to blood-stage infection. These results are in close agreement with earlier studies, where repetitive exposure of live $P$. yoelii sporozoites under antimalarial drug cover delivered sterile immunity (Inoue and Culleton 2011, Bijker et al. 2013, Behet et al. 2014, Peng et al. 2014, Bhardwaj et al. 2016, Zenklusen et al. 2018, Siddiqui et al. 2021).

Furthermore, we also found that the induced immunity is associated with the significant up-regulation of pro-inflammatory cytokines (IFN- $\gamma, \mathrm{TNF}-\alpha, \mathrm{IL}-12$, and iNOS) and downregulation of anti-inflammatory cytokines (IL-10 and TGF- $\beta$ ) mRNA levels in the liver and spleen of the CPS-HF immunised group compared with control. These results suggested the involvement of pro-inflammatory cytokines in sporozoite-based immunisation in the mouse model (Belnoue et al. 2004, Friesen et al. 2010, Bijker et al. 2013, Haussig et al. 2014).

Previous studies also suggested the role of differential cytokine expression in host (mice) susceptibility to different parasite strains (Bhardwaj et al. 2016, Burrack et al. 2019, Sato et al. 2019). Interestingly, we observed up-regulation of IFN- $\gamma$, TNF- $\alpha$, IL-12 and iNOS mRNA expression from liver HMNC and spleen of CPS-HF immunised group.

It has also been observed that the treatment of sporozoite-infected hepatocytes with IFN- $\gamma$ causes clearance of parasites under in vitro culture conditions (Plasmodium berghei Vincke et Zips, 1948 and Plasmodium falciparum Welch, 1897) (Ferreira et al. 1986, Gun et al. 2014, Lelliott and Coban 2016, Tweedell et al. 2018).
In vivo treatment with IFN- $\gamma$ also provide partial protection against challenge with sporozoites of $P$. berghei and Plasmodium cynomolgi Mayer, 1908 in the mice and monkey malaria model (Gun et al. 2014, Keitany et al. 2014, Lelliott and Coban 2016). Similarly, IFN- $\gamma$ and TNF- $\alpha$ also showed to be involved in the protection of mice against $P$. yoelii sporozoites challenge (Doll and Harty 2014). IL-12 and iNOS cytokines were previously shown to be involved in sterile protection in the mice after sporozoite challenge (Ferreira et al. 1986, Romero et al. 2007, Frevert and Krzych 2015) and inhibition of iNOS via treatment with specific NO inhibitor, such as S-methyl-thiourea completely reverse the protection in mice (Percário et al. 2012, Mendes et al. 2018). It is known that NO production occurs through the IFN- $\gamma$ and IL-12 induction by direct or indirect mode to activate the iNOS gene expression (Blanchette et al. 2003, Salim et al. 2016). Thus, our study showed that halofantrine is an effective chemoprophylactic drug, and sporozoite immunization under HF chemoprophylaxis produces robust protective immunity against subsequent sporozoite challenge.

Author contributions. Conceptualisation - A.J.S., J.B. and M.G.; methodology - W.S.H., A.J. and S.A.A.; validation - M.A. M. Sand S.J.; formal analysis - M.A., M.G. and A.J.S.; investigation - A.J., S.A.A, R.B. and J.B.; data curation - M.A., A.J., W.S.H., S.A.A. and M.S.; writing (original draft preparation) - A. J.S. J.B. and M.G.; writing (review and editing) - M.G., M.A. and J.B.; visualisation - A.J., M.S. and W.S.H.; supervision - A.J.S., M.A. and J.B.; project administration - A.J.S. All authors have read and agreed to the published version of the manuscript.

Acknowledgements. This research has been funded by Scientific Research Deanship at the University of Hail, Hail, Saudi Arabia through project number RG-20128. We would like to thank and appreciate all the support and technical assistance provided by S. Puri lab at CSIR-CDRI, Lucknow, India during this study.

\section{REFERENCES}

Abuga K.M., Jones-Warner W., Hafalla J.C.R. 2021: Immune responses to malaria pre-erythrocytic stages: implications for vaccine development. Parasite Immunol. 43: e12795.

Behet M.C., Foquet L., van Gemert G.J., Bijker E.M., Meuleman P., Leroux-Roels G., Hermsen C.C., Scholzen A., SAuerwein R.W. 2014: Sporozoite immunization of human volunteers under chemoprophylaxis induces functional antibodies against pre-erythrocytic stages of Plasmodium falciparum. Malar. J. 13: 136.

Belnoue E., Costa F.T., Frankenberg T., Vigário A.M., Voza T., Leroy N., Rodrigues M.M., Landau I., Snounou G., RÉnia L. 2004: Protective T cell immunity against malaria liver stage after vaccination with live sporozoites under chloroquine treatment. J. Immunol. 172: 2487-2495.

Bhardwaj J., Siddiqui A.J., Goyal M., Prakash K., Soni A., PURI S.K. 2016: Repetitive live sporozoites inoculation under arteether chemoprophylaxis confers protection against subsequent sporozoite challenge in rodent malaria model. Acta Trop. 158: $130-138$.

Bhardwaj J., Siddiqui A.J., Goyal M., Prakash K., Soni A., Puri S.K., Srivastava M. 2015: Host immune response is severely compromised during lethal Plasmodium vinckei infection. Parasitol. Res. 114: 3445-3457.

Bijker E.M., Bastiaens G.J., Teirlinck A.C., van Gemert G.J., Graumans W., van de Vegte-Bolmer M., Siebelink-Stoter R., Arens T., Teelen K., Nahrendorf W., Remarque E.J., Roeffen W., Jansens A., Zimmerman D., Vos M., van Schaijk B.C., Wiersma J., van der Ven A.J., de Mast Q., van Lieshout L., Verweij J.J., Hermsen C.C., Scholzen A., Sauerwein R.W. 2013: Protection against malaria after immunization by chloroquine prophylaxis and sporozoites is mediated by preerythrocytic immunity. Proc. Natl. Acad. Sci. U.S.A. 110: 7862-7867.

Bijker E.M., Nganou-Makamdop K., van Gemert G.J., Zavala F., Cockburn I., Sauerwein R.W. 2015: Studying the effect of chloroquine on sporozoite-induced protection and immune responses in Plasmodium berghei malaria. Malar. J. 14: 130.

Blanchette J., Jaramillo M., Olivier M. 2003: Signalling events involved in interferon-gamma-inducible macrophage nitric oxide generation. Immunology 108: 513-522.

Burrack K.S., Hart G.T., Hamilton S.E. 2019: Contributions of natural killer cells to the immune response against Plasmodium. Malar. J. 18: 321. 
Doll K.L., Harty J.T. 2014: Correlates of protective immunity following whole sporozoite vaccination against malaria. Immunol. Res. 59: 166-176.

Ferreira A., Schofield L., Enea V., Schellekens H., van der Meide P., Collins W.E., Nussenzweig R.S., NussenZWEIG V. 1986: Inhibition of development of exoerythrocytic forms of malaria parasites by gamma-interferon. Science 232 $881-884$.

Frevert U., Krzych U. 2015: Plasmodium cellular effector mechanisms and the hepatic microenvironment. Front. Microbiol. 6: 482.

Friesen J., Silvie O., Putrianti E.D., Hafalla J.C., MaTUSCHEWSKi K., BorRmANN S. 2010: Natural immunization against malaria: causal prophylaxis with antibiotics. Sci. Transl. Med. 2: 40ra49.

Frimpong A., Kusi K.A., Ofori M.F., Ndifon W. 2018: Novel strategies for malaria vaccine design. Front. Immunol. 9: 2769.

Gun S.Y., Claser C., Tan K.S., Rénia L. 2014: Interferons and interferon regulatory factors in malaria. Mediators Inflamm. 2014: 243713.

Haidar I., Harding I.H., Bowater I.C., McDowall A.W. 2019: Physical characterization of halofantrine-encapsulated fat nanoemulsions. J. Pharm. Sci. 108: 2153-2161.

Haussig J.M., Burgold J., Hafalla J.C., Matuschewski K., Koois T.W. 2014: Signatures of malaria vaccine efficacy in ageing murine immune memory. Parasite Immunol. 36: 199-206.

Hemingway J., Shretta R., Welles T.N., Bell D., Dimdie A.A., Achee N., Qi G. 2016: Tools and strategies for malaria control and elimination: what do we need to achieve a grand convergence in malaria? PLoS Biol. 14: e1002380.

Inoue M., Culleton R.L. 2011: The intradermal route for inoculation of sporozoites of rodent malaria parasites for immunological studies. Parasite Immunol. 33: 137-142.

Keitany G.J., Sack B., Smithers H., Chen L., Jang I.K., Sebastian L., Gupta M., Sather D.N., Vignali M., Vaughan A.M., KAPPE S.H., WANG R. 2014: Immunization of mice with live-attenuated late liver stage-arresting Plasmodium yoelii parasites generates protective antibody responses to preerythrocytic stages of malaria. Infect. Immun. 82: 5143-5153.

Kolade Y.T., Babalola C.P., Olaniyi A.A., Scriba G.K. 2008: Effect of kolanut on the pharmacokinetics of the antimalarial drug halofantrine. Eur. J. Clin. Pharmacol. 64: 77-81.

Kurtovic L., Boyle M.J., Opi D.H., Kennedy A.T., Tham W.H., Reiling L., Chan J.A., Beeson J.G. 2020: Complement in malaria immunity and vaccines. Immunol. Rev. 293: 38-56.

Lelliott P.M., CoBan C. 2016: IFN- $\gamma$ protects hepatocytes against Plasmodium vivax infection via LAP-like degradation of sporozoites. Proc. Natl. Acad. Sci. U.S.A. 113: 6813-6815.

Mendes A.M., Machado M., Gonçalves-Rosa N. 2018: A Plasmodium berghei sporozoite-based vaccination platform against human malaria. NPJ Vaccines 3: 33.

Mordmuller B., Surat G., Lagler H., Chakravarty S., Ishizuka A.S., Lalremruata A., Gmeiner M., Campo J.J., Esen M., Ruben A.J., Held J., Calle C.L., Mengue J.B., Gebru T., Ibanez J., Sulyok M., James E.R., Billingsley P.F., Natasha K.C., Manou A., Murshedkar T., Gunasekera A., EAppen A.G., Li T., Stafford R.E., Li M., Felgner P.L., Seder R.A., Richie T.L., Sim B.K., Hoffman S.L., Kremsner P.G. 2017: Sterile protection against human malaria by chemoattenuated PfSPZ vaccine. Nature 542: 445-449.

Peng X., Keitany G.J., Vignali M., Chen L., Gibson C., Choi K., Huang F., Wang R. 2014: Artesunate versus chloroquine infection-treatment-vaccination defines stage-specific immune responses associated with prolonged sterile protection against both pre-erythrocytic and erythrocytic Plasmodium yoelii infection. J. Immunol. 193: 1268-1277.

Received 30 June 2021

Accepted 28 November 2021

Published online 3 February 2022

Cite this article as: Siddiqui A.J., Bhardwaj J., Hamadou W.S., Goyal M., Jahan S., Ashraf S.A., Jamal A., Sharma P., Sachidanandan M., Badraoui R., Snoussi M., Adnan M. 2022: Impact of chemoprophylaxis immunisation under halofantrine (CPS-HF) drug cover in Plasmodium yoelii Swiss mice malaria model. Folia Parasitol. 69: 003.

Folia Parasitologica 2022, 69: 003

Page 10 of 10
Percário S., Moreira D.R., Gomes B.A., Ferreira M.E., Gonçalves A.C., Laurindo P.S., Vilhena T.C., Dolabela M.F., Green M.D. 2012: Oxidative stress in malaria. Int. J. Mol. Sci. 13: 16346-16372.

Prakash K., Goyal M., Soni A., Siddiqui A.J., Bhardwaj J., PURi S.K. 2014: Molecular cloning and biochemical characterization of iron superoxide dismutase from the rodent malaria parasite Plasmodium vinckei. Parasitol. Int. 63: 817-825.

Romero J.F., Ibrahim G.H., RengGli J., Himmelrich H., GraBer P., CORRAdin G. 2007: IL-12p40-independent induction of protective immunity upon multiple Plasmodium berghei irradiated sporozoite immunizations. Parasite Immunol. 29: 541-548.

Salim T., Sershen C.L., May E.E. 2016: Investigating the role of TNF- $\alpha$ and IFN- $\gamma$ activation on the dynamics of iNOS gene expression in LPS stimulated macrophages. PLoS One 11: e0153289.

Sato Y., Ries S., Stenzel W., Fillatreau S., Matuschewski K. 2019: The liver-stage Plasmodium infection is a critical checkpoint for development of experimental cerebral malaria. Front. Immunol. 10: 2554.

Siddiqui A.J., Adnan M., Jahan S., Redman W., Saeed M., Patel M. 2020a: Neurological disorder and psychosocial aspects of cerebral malaria: what is new on its pathogenesis and complications? A minireview. Folia Parasitol. 67: 015.

Siddiqui A.J., Bhardwaj J., Goyal M., Prakash K., Adnan M., Alreshidi M.M., Patel M., Soni A., Redman W. 2020b: Immune responses in liver and spleen against Plasmodium yoelii pre-erythrocytic stages in Swiss mice model. J. Adv. Res. 24: 29-41.

Siddiqui A.J., Bhardwaj J., Goyal M., Prakash K., Soni A., TIWARI V., PURI S.K. 2015: Assessment of real-time method to detect liver parasite burden under different experimental conditions in mice infected with Plasmodium yoelii sporozoites. Microb. Pathog. 89: 35-42.

Siddiqui A.J., Bhardwaj J., Hamadou W.S., Goyal M., Ashraf S.A., Jahan S., Jamal A., Sharma P., Sachidanandan M., Badraoui R., Adnan M. 2021: Chemoprophylaxis under sporozoites-lumefantrine (CPS-LMF) immunization induce protective immune responses against Plasmodium yoelii sporozoites infection in mice. 3 Biotech 11: 465.

Siddiqui A.J., BhardwaJ J., PURi S.K. 2012: mRNA expression thal and nonlethal Plasmodium vinckei parasites. Parasitol. Res. 110: $1517-1524$

Soni A., Goyal M., Prakash K., Bhardwaj J., Siddiqui A.J., PURI S.K. 2015: Cloning, expression and functional characterization of heme detoxification protein (HDP) from the rodent malaria parasite Plasmodium vinckei. Gene 566: 109-119.

Tweedell R.E., Qi L., Sun Z., Dinglasan R.R. 2018: Kupffer cells survive Plasmodium berghei sporozoite exposure and respond with a rapid cytokine release. Pathogens 7: 91.

Varo R., Balanza N., Mayor A., Bassat Q. 2021: Diagnosis of clinical malaria in endemic settings. Expert Rev. Anti Infect. Ther. 19: 79-92.

WHO 2019: World Health Organization. World Malaria Report Geneva. (2019). Available online at: http://www.who.int/malaria/ publications/world-malaria-report-2019/en/.

Zenklusen I., Jongo S., Abdulla S., Ramadhani K., Lee Sim B.K., Cardamone H., Flannery E.L., Nguyen T., Fishbaugher M., Steel R.W.J., Betz W., Carmago N., Mikolajczak S., Kappe S.H.I., Hoffman S.L., Sack B.K., DAUBenberger C. 2018: Immunization of malaria-preexposed volunteers with PfSPZ vaccine elicits long-lived IgM invasion-inhibitory and complement-fixing antibodies. J. Infect. Dis. 217: 1569-1578. of cytokines and its impact on outcomes after infection with le- 